\title{
Article
}

\section{Eg5 as a Prognostic Biomarker and Potential Therapeutic Target for Hepatocellular Carcinoma}

\author{
Yu-Yun Shao ${ }^{1,2} \oplus$, Nai-Yun Sun ${ }^{1}$, Yung-Ming Jeng ${ }^{3,4}$, Yao-Ming Wu ${ }^{5}$, Chiun Hsu ${ }^{1,2,6}$, Chih-Hung Hsu ${ }^{1,2,6}$, \\ Hey-Chi Hsu ${ }^{3,4}$, Ann-Lii Cheng ${ }^{1,2,6,7}$ and Zhong-Zhe Lin ${ }^{2,6,7, *}$
}

1 Graduate Institute of Oncology, National Taiwan University College of Medicine, 1, Sec. 1, Ren'ai Rd., Taipei 100, Taiwan; yuyunshao@gmail.com (Y.-Y.S.); naiyunsun@hotmail.com (N.-Y.S.); hsuchiun@gmail.com (C.H.); chihhunghsu@ntu.edu.tw (C.-H.H.); alcheng@ntu.edu.tw (A.-L.C.)

2 Department of Oncology, National Taiwan University Hospital, 7, Chung-Shan S. Rd., Taipei 100, Taiwan

3 Department of Pathology, National Taiwan University Hospital, 7, Chung-Shan S. Rd., Taipei 100, Taiwan; mrna0912@gmail.com (Y.-M.J.); heychi@ntu.edu.tw (H.-C.H.)

4 Graduate Institute of Pathology, National Taiwan University College of Medicine, 1, Sec. 1, Ren'ai Rd., Taipei 100, Taiwan

5 Department of Surgery, National Taiwan University Hospital, 7, Chung-Shan S. Rd., Taipei 100, Taiwan; wyaoming@ntuh.gov.tw

6 Department of Medical Oncology, National Taiwan University Cancer Center, 57, Lane 155, Sec. 3, Keelung Rd., Taipei 106, Taiwan

7 Department of Internal Medicine, National Taiwan University Hospital, 7, Chung-Shan S. Rd., Taipei 100, Taiwan

* Correspondence: zzlin7460@ntu.edu.tw; Tel.: +886-972-651672; Fax: +886-2-23711174

check for

updates

Citation: Shao, Y.-Y.; Sun, N.-Y.; Jeng, Y.-M.; Wu, Y.-M.; Hsu, C.; Hsu, C.-H.; Hsu, H.-C.; Cheng, A.-L.; Lin, Z.-Z. Eg5 as a Prognostic Biomarker and Potential Therapeutic Target for Hepatocellular Carcinoma. Cells 2021, 10, 1698. https://doi.org/10.3390/ cells10071698

Academic Editors: Kyu Yun Jang and See-Hyoung Park

Received: 24 May 2021

Accepted: 1 July 2021

Published: 5 July 2021

Publisher's Note: MDPI stays neutral with regard to jurisdictional claims in published maps and institutional affiliations.

Copyright: (c) 2021 by the authors. Licensee MDPI, Basel, Switzerland. This article is an open access article distributed under the terms and conditions of the Creative Commons Attribution (CC BY) license (https:// creativecommons.org/licenses/by/ $4.0 /)$.
Abstract: Background: The kinesin $E g 5$, a mitosis-associated protein, is overexpressed in many cancers. Here we explored the clinical significance of $E g 5$ in hepatocellular carcinoma (HCC). Methods: HCC tissues from surgical resection were collected. Total RNA was prepared from tumorous and nontumorous parts. Eg5 expression levels were correlated with overall survival (OS) and disease-free survival (DFS). In vitro efficacy of LGI-147, a specific $E g 5$ inhibitor, was tested in HCC cell lines. In vivo efficacy of $E g 5$ inhibition was investigated in a xenograft model. Results: A total of 108 HCC samples were included. The patients were divided into three tertile groups with high, medium, and low Eg5 expression levels. OS of patients with low Eg 5 expression was better than that of patients with medium and high $E g 5$ expression (median, 155.6 vs. 75.3 vs. 57.7 months, $p=0.002)$. DFS of patients with low $E g 5$ expression was also better than that of patients with medium and high $E g 5$ expression (median, 126.3 vs. 46.2 vs. 39.4 months, $p=0.001$ ). In multivariate analyses, the associations between $E g 5$ expression and OS ( $p<0.001)$ or DFS remained $(p<0.001)$. LGI-147 reduced cell growth via cell cycle arrest and apoptosis and induced accumulation of abnormal mitotic cells. In the xenograft model, the tumor growth rate under LGI-147 treatment was significantly slower than under the control. Conclusion: High Eg5 expression was associated with poor HCC prognosis. In vitro and in vivo evidence suggests that $E g 5$ may be a reasonable therapeutic target for HCC.

Keywords: Eg5; hepatocellular carcinoma; kinesin; mitosis; prognosis

\section{Introduction}

Treatment for unresectable hepatocellular carcinoma (HCC) remains challenging despite improvements in treatment modalities including antiangiogenic targeted therapy and immune checkpoint inhibitors [1]. For diseases refractory or unamenable to transarterial chemoembolization, combined targeted therapy and immunotherapy can produce an objective response rate of approximately $30 \%$ [2-5], which leaves much room for improvement. Moreover, patients who fail first-line systemic therapy exhibit poor prognosis [6]. Therefore, novel modalities of systemic therapies for HCC are urgently required. 
We and other investigators have discovered that mitosis regulators, such as Aurora kinases A and B, are frequently overexpressed in HCC cells and have been associated with poor HCC prognosis [7-9]. Kinesins are a superfamily of motor proteins that participate in the organelle transport and mitosis [10,11]. Overexpression of Eg5, a kinesin, may lead to genomic instability and tumor formation in mice [12]. High Eg5 expression in tumor tissues is also associated with poor prognosis in breast and laryngeal cancers [13,14].

In addition, mitosis regulators also can serve as potential cancer treatment therapeutic targets. Taxanes and vinka alkaloids, chemotherapeutic agents effective against multiple cancers, interfere with microtubules and hence mitotic function [15]. Numerous studies have indicated the potential of kinesin inhibitors as treatment for various cancers $[10,16]$. Among them, Eg5 inhibitors have been reported to be effective in preclinical models of melanoma as well as breast, ovarian, and prostate cancers [17-20].

The role of Eg5 in prognosis prediction and as a therapeutic target related to HCC is unclear. We examined the association between Eg5 expression in surgically resected tumor tissues and HCC prognosis. We also tested the in vitro and in vivo efficacy of Eg5 inhibition against HCC.

\section{Methods}

\subsection{Patient Samples}

We assessed unifocal primary HCC tissues from 108 patients who underwent surgical total tumor resection between January 1987 and January 2008. Comprehensive pathologic assessments and regular clinical follow-ups were performed at the National Taiwan University Hospital (NTUH), as described previously [7]. Patients with evidence of regional lymph node or distant metastasis were excluded. This study was approved by the Research Ethics Committee of NTUH.

\subsection{Quantitative Reverse Transcription-Polymerase Chain Reaction}

The extraction of total RNA and complementary DNA of paired HCCs and nontumorous liver tissues was prepared as described previously [21]. Gene expression assays for $E g 5$ were performed using quantitative reverse transcription polymerase chain reaction with the TaqMan ${ }^{\circledR}$ Gene Expression Master Mix and an Eg5 probe (Hs00189698_m1), with GAPDH as a control (Hs99999905_m1; Applied Biosystems, Foster City, CA, USA). The expression levels of $E g 5$ and GAPDH were determined through 45 thermal cycles of $30 \mathrm{~s}$ at $95^{\circ} \mathrm{C}$ and $60 \mathrm{~s}$ at $60^{\circ} \mathrm{C}$. All experiments were performed in duplicate. Quantitative data were expressed as the numbers of cycles required to reach a specific threshold of detection $\left(C_{T}\right.$ value $)$ during the exponential amplification phase. The relative quantification of Eg5 expression was calculated using the comparative threshold cycle $\left(2^{-\Delta \Delta \mathrm{CT}}\right)$ method

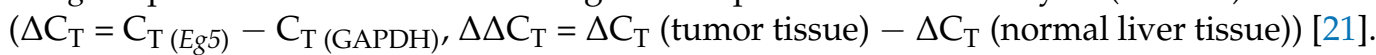

\subsection{Cell Culture and Reagents}

The liver cancer cell lines HepG2, Hep3B, and PLC5 were maintained in Dulbecco's modified Eagle's medium plus 10\% fetal bovine serum, supplemented with $100 \mathrm{U} / \mathrm{mL}$ penicillin and $100 \mu \mathrm{g} / \mathrm{mL}$ streptomycin. Cells were cultured in a humidified incubator with $5 \% \mathrm{CO}_{2}$ at an air temperature of $37^{\circ} \mathrm{C}$.

LGI-147 was provided by Novartis Pharma AG (Basel, Switzerland). The biochemical half maximal inhibitory concentration $\left(\mathrm{IC}_{50}\right)$ of LGI-147 for Eg5 is $0.6 \mathrm{nM}$ (unpublished data provided by Novartis Pharma AG).

\subsection{Cell Viability}

A total of $5 \times 10^{4}$ liver cancer cells were seeded in 6-well plates. After overnight culture, cells were treated with dimethyl sulfoxide or LGI-147 for $72 \mathrm{~h}$. Cell viability was quantified using the trypan blue exclusion assay as described previously [7]. 


\subsection{Cell-Free Kinesin ATPase End-Point Assay}

Purified kinesin motor proteins, namely Eg5, centromere-associated protein E (CENPE), mitotic kinesin-like protein-1 (MKLP-1), and BimC, were purchased from Cytoskeleton, Inc. (Denver, CO, USA). We used the HTS Kinesin ATPase End-Point Biochem kit (Cytoskeleton, Inc.) to examine kinesin activity [22]. Inhibition of kinesin activity was calculated using the following formula: average $\%=($ average untreated - average treated)/average untreated) $\times 100$.

\subsection{Immunofluorescence Staining}

Morphologic changes in the mitotic spindles, centromeres, and chromosomes of the liver cancer cells were detected through immunofluorescence staining, which was performed as previously described [8]. Primary antibodies against $\alpha$-tubulin (1:100, Sigma-Aldrich) or $\gamma$-tubulin (1:100, Sigma-Aldrich) were used. Cells were then incubated with fluorescein-conjugated secondary antibodies (1:200; Santa Cruz Biotechnology, Inc.) for $1 \mathrm{~h}$. Nuclei were counterstained with $0.5 \mu \mathrm{g} / \mathrm{mL} 4^{\prime}, 6$-diamidino-2-phenylindole (DAPI) for $15 \mathrm{~min}$. Images were captured using a confocal microscope (Leica TCS SP2, Wetzlar, Germany).

\subsection{Cell Cycle and Apoptosis Analyses}

Cells in logarithmic growth were incubated with either LGI-147 or dimethyl sulfoxide for 24 to $72 \mathrm{~h}$. Cells were trypsinized and fixed in 70\% methanol overnight and labeled with 0.5 to $1 \mathrm{~mL}$ propidium iodide at $50 \mu \mathrm{g} / \mathrm{mL}$. Cell cycle profiles were determined using a FACSCaliber (Becton Dickinson, San Jose, CA, USA).

The sub-G1 assay by flow cytometry was used to determine apoptotic cell numbers. Western blotting was performed according to standard protocols using an anti-cleaved poly(ADP-ribose) polymerase (PARP) antibody (Cell Signaling Technology, Beverly, MA, USA) and an anti- $\beta$-actin antibody (Sigma-Aldrich) to detect apoptotic signals.

\subsection{Xenograft Animal Studies}

Animal studies were conducted according to the guidelines of the Institutional Animal Care and Use Committee of NTUH. LGI-147 was prepared in 20\% Captisol (Captisol, San Diego, CA, USA) solution. All experiments were performed on 5-week-old male BALB/c nude mice purchased from BioLASCO, Ltd. (Taipei, Taiwan). PLC5 cells were injected subcutaneously into the right flanks $\left(2 \times 10^{6} /\right.$ flank in $\left.200 \mu \mathrm{L}\right)$ of the mice. When tumor volume reached approximately $200 \mathrm{~mm}^{3}$, the mice were treated with intravenous injection of LGI-147 or a vehicle twice a week. Tumor size was estimated twice a week, and the body weight was monitored daily.

\subsection{Statistical Analysis}

All statistical analyses were performed using SAS software version 9.4 (SAS Institute Inc., Cary, NC, USA). A two-sided $p$ value of $\leq 0.05$ was considered statistically significant. For continuous variables such as tumor size and $E g 5$ expression, either the independent $t$ test or one-way analysis of variance was used for between-group comparisons. The Pearson correlation coefficient was calculated to examine the correlation between age and Eg5 expression. The Kaplan-Meier method was used to estimate survival outcomes. To compare survival between groups, the log-rank test and a Cox proportional hazards model were used in univariate and multivariate analysis, respectively. Overall survival (OS) was defined as the period from the surgery date until the date of death. Disease-free survival (DFS) denoted the period from the surgery date until tumor recurrence or the date of death, whichever occurred first. Minimal follow-up duration was 5 years. At the end of the follow-up session in August 2019, only 17 patients were still alive. 


\section{Results}

\subsection{Eg5 Expression and HCC Prognosis}

A total of 108 unifocal primary HCC samples from patients who received curative surgery for HCC were included. The mean patient age was 54.7 years, and $19 \%$ were female (Table 1). Hepatitis B virus and hepatitis C virus infection was detected in $69 \%$ and $29 \%$ of patients, respectively. The mean RNA expression of $E g 5$ in tumor tissues compared with that in nontumor tissues was 8.3. Eg5 expression was not significantly associated with patient demographic characteristics, tumor extent, or tumor grade (Table 1).

Table 1. Patient characteristics and their associations with Eg5 expression.

\begin{tabular}{|c|c|c|c|}
\hline \multirow{2}{*}{ Variables } & \multirow{2}{*}{$\mathbf{N}(\%)$} & \multicolumn{2}{|c|}{$E g 5^{+}$} \\
\hline & & Mean \pm SD & $p$ \\
\hline Total & $108(100)$ & $8.3 \pm 16.0^{\#}$ & \\
\hline Mean age (SD, years) & $54.7(13.4)^{\#}$ & & \\
\hline Gender & & & 0.887 \\
\hline Female & $21(19)$ & $8.7 \pm 10.6$ & \\
\hline Male & $87(81)$ & $8.2 \pm 17.1$ & \\
\hline Hepatitis virus & & & \\
\hline HBsAg positive & $75(69)$ & $8.3 \pm 15.6$ & 0.964 \\
\hline Anti-HCV positive & $31(29)$ & $6.9 \pm 16.6$ & 0.578 \\
\hline AJCC stage & & & 0.573 \\
\hline I & $46(43)$ & $7.5 \pm 19.8$ & \\
\hline II & $32(30)$ & $7.0 \pm 8.5$ & \\
\hline III & $30(28)$ & $10.9 \pm 15.8$ & \\
\hline Tumor size & & & 0.835 \\
\hline$>5 \mathrm{~cm}$ & $48(44)$ & $8.7 \pm 19.3$ & \\
\hline$\leq 5 \mathrm{~cm}$ & $60(56)$ & $8.0 \pm 12.9$ & \\
\hline Tumor grade & & & 0.683 \\
\hline 1 & $26(24)$ & $10.3 \pm 24.4$ & \\
\hline 2 & $51(47)$ & $7.0 \pm 14.0$ & \\
\hline 3 & $31(29)$ & $8.8 \pm 9.1$ & \\
\hline $\mathrm{AFP}>400 \mathrm{ng} / \mathrm{mL}$ & $40(37)$ & $9.4 \pm 14.8$ & 0.573 \\
\hline Child-Pugh status & & & 0.828 \\
\hline $\mathrm{A}$ & $100(93)$ & $8.4 \pm 16.4$ & \\
\hline $\mathrm{B}$ & $8(7)$ & $7.1 \pm 9.7$ & \\
\hline
\end{tabular}

Abbreviations: $\mathrm{SD}=$ standard deviation; $\mathrm{HBsAg}=$ hepatitis B virus surface antigen; $\mathrm{HCV}=$ hepatitis $\mathrm{C}$ virus $\mathrm{AJCC}=$ American Joint Committee on Cancer; AFP $=\alpha$-fetoprotein. ${ }^{\#}$ Age had a weakly positive correlation with Eg5 expression $(\mathrm{r}=0.013, p=0.897) .{ }^{\dagger}$ Calculated using the method described in Section 2.2. $p$ values were conducted using the independent $t$ test or one-way analysis of variance.

The patients were divided into three tertile groups with high (>5.33), medium (1.4-5.33), and low Eg5 $(<1.4)$ mRNA expression levels. The 24-month OS rates of patients with low, medium, and high $E g 5$ expression were $75 \%, 63.9 \%$, and $41.7 \%$, respectively. The median OS of patients with low, medium, and high Eg5 expression was 155.6, 75.3, and 57.7 months, respectively (Figure 1A). The 24-month DFS rates of patients with low, medium, and high Eg5 expression were $58.3 \%, 50.0 \%$, and $25.0 \%$, respectively. The median DFS of patients with low, medium, and high Eg5 expression was 126.3, 46.2, and 39.4 months, respectively (Figure 1B). Thus, the patients with low Eg5 expression exhibited the best survival outcomes, as compared with two groups of patients with high and medium Eg5 expression, in OS $(p=0.002)$ and DFS ( $p=0.001)$. In other words, high Eg5 expression seems to correlate with tumor progression and hence poor patient survival.

After adjustment for other clinicopathological variables, including gender, age, tumor stage, hepatitis etiology, and $\alpha$-fetoprotein level, low Eg5 expression remained an independent predictor of better OS (hazard ratio (HR) 0.377, $p<0.001$ ) and DFS (HR 0.334, $p<0.001$; Table 2). 
A

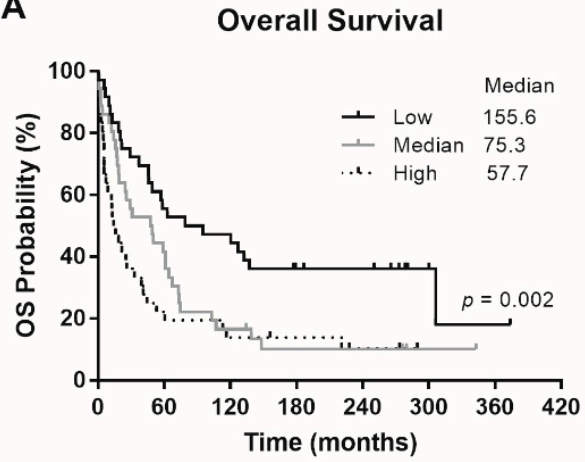

B

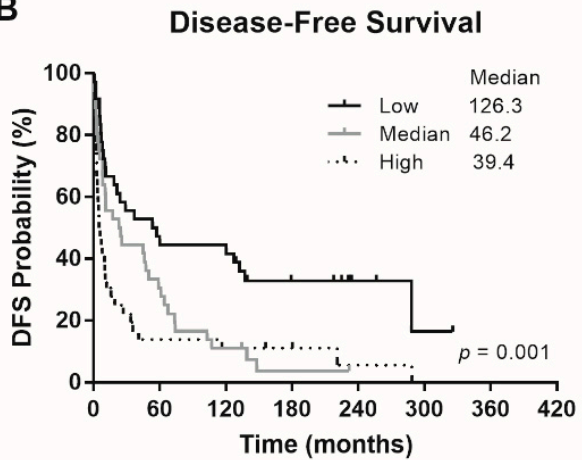

Figure 1. Survival outcomes of the patients. (A) Overall survival (OS) and (B) disease-free survival (DFS) according to patients' Eg5 expression levels. $p$ values were conducted using the log-rank test.

Table 2. Multivariate analysis of potential predictors of overall survival and disease-free survival using Cox proportional hazards models.

\begin{tabular}{ccccccc}
\hline \multirow{2}{*}{ Variables } & \multicolumn{3}{c}{ Overall Survival } & \multicolumn{3}{c}{ Disease-Free Survival } \\
\cline { 2 - 7 } & $\boldsymbol{p}$ & HR & $\mathbf{9 5 \% ~ C I ~}$ & $\boldsymbol{p}$ & HR & $\mathbf{9 5 \% ~ C I ~}$ \\
\hline Eg5 low (vs. high) & $<0.001$ & 0.377 & $0.214-0.665$ & $<0.001$ & 0.334 & $0.187-0.596$ \\
Eg5 medium (vs. high) & 0.391 & 0.793 & $0.468-1.346$ & 0.352 & 0.773 & $0.449-1.330$ \\
Age & 0.133 & 1.014 & $0.996-1.033$ & 0.594 & 1.005 & $0.988-1.022$ \\
Male (vs. female) & 0.924 & 0.971 & $0.537-1.759$ & 0.286 & 0.732 & $0.412-1.299$ \\
HBsAg positive & 0.007 & 2.580 & $1.302-5.112$ & 0.065 & 1.880 & $0.961-3.675$ \\
Anti-HCV positive & 0.063 & 1.761 & $0.969-3.201$ & 0.188 & 1.498 & $0.821-2.733$ \\
AJCC stage I (vs. III) & $<0.001$ & 0.314 & $0.184-0.538$ & 0.004 & 0.464 & $0.274-0.784$ \\
AJCC stage II (vs. III) & $<0.001$ & 0.305 & $0.168-0.552$ & $<0.001$ & 0.372 & $0.209-0.663$ \\
AFP > 400 ng/mL & 0.486 & 1.185 & $0.735-1.911$ & 0.056 & 1.599 & $0.988-2.589$ \\
Child B (vs. A) & 0.355 & 1.458 & $0.656-3.237$ & 0.306 & 1.531 & $0.677-3.460$ \\
\hline
\end{tabular}

Abbreviations: $\mathrm{OS}=$ overall survival; $\mathrm{DFS}=$ disease-free survival; $\mathrm{HR}=$ hazard ratio; $\mathrm{CI}$ = confidence interval; $\mathrm{HBs} \mathrm{Ag}=$ hepatitis $\mathrm{B}$ virus surface antigen; $\mathrm{HCV}=$ hepatitis $\mathrm{C}$ virus; $\mathrm{AJCC}=$ American Joint Committee on Cancer; $\mathrm{AFP}=\alpha$-fetoprotein .

\subsection{Eg5 Inhibition Reduced HCC Cell Viability}

Because our results suggested that high $E g 5$ expression seems to correlate with tumor progression and hence poor patient survival, we then tried to test the effect of $E g 5$ inhibition on HCC cells. We first performed the trypan blue exclusion assay to test the antiproliferative effects of LGI-147, an Eg5 inhibitor, on multiple HCC cell lines, including HepG2, Hep3B, and PLC5 cells. LGI-147 reduced cell viability in all cell lines in a dose-dependent manner (Figure 2A). The $\mathrm{IC}_{50}$ at $72 \mathrm{~h}$ for the HepG2, Hep3B, and PLC5 cells were 53.59, 59.6, and $43.47 \mathrm{pM}$, respectively. We examined the specific kinase inhibitory activity of LGI-147 using the cell-free kinesin ATPase assay. LGI-147 inhibited the activity of $E g 5$ but not that of other kinesins such as CENP-E, MKLP-1, and BimC (Figure 2B).

\subsection{Cellular Effects of Eg5 Inhibition in HCC Cells}

To analyze the mitotic interference of $E g 5$ inhibition, we examined the morphological changes in mitotic spindles and chromosomes in HCC cells treated with LGI-147. The accumulation of abnormal mitotic cells induced by LGI-147 was dose dependent. After treatment with $40 \mathrm{pM}$ of LGI-147, more than $75 \%$ of HCC cells showed abnormal mitotic features (Figure 2C,D). LGI-147 induced an accumulation of prometaphase cells with disturbed centrosome maturation and abnormal monopolar spindles (Figure $3 \mathrm{~A}-\mathrm{C}$ ). 
A

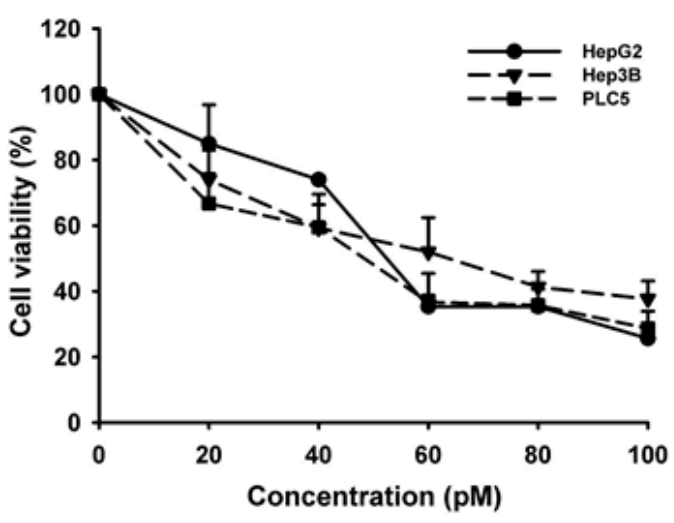

C

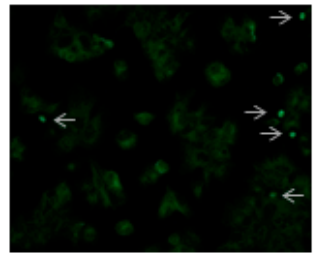

$0 \mathrm{pM}$

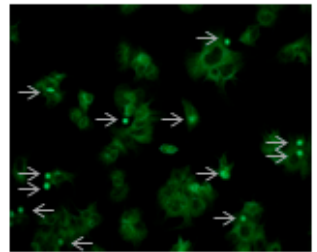

$20 \mathrm{pM}$

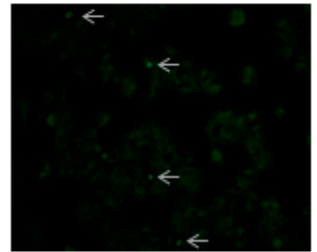

$2.5 \mathrm{pM}$

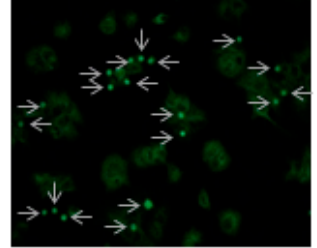

$40 \mathrm{pM}$

B

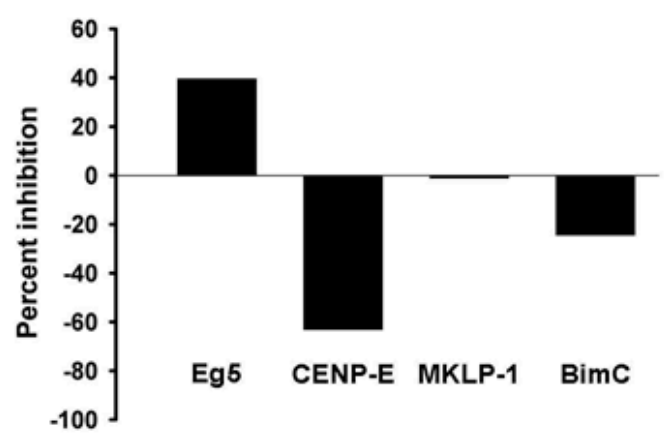

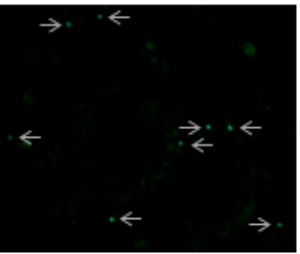

$5 \mathrm{pM}$

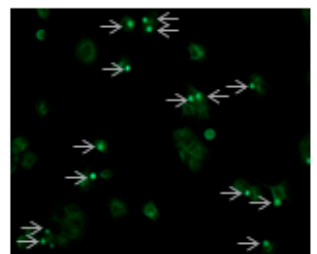

$80 \mathrm{pM}$

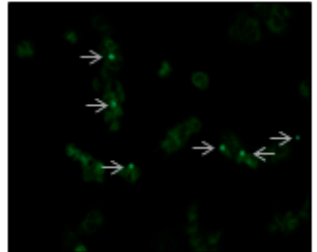

$10 \mathrm{pM}$

D

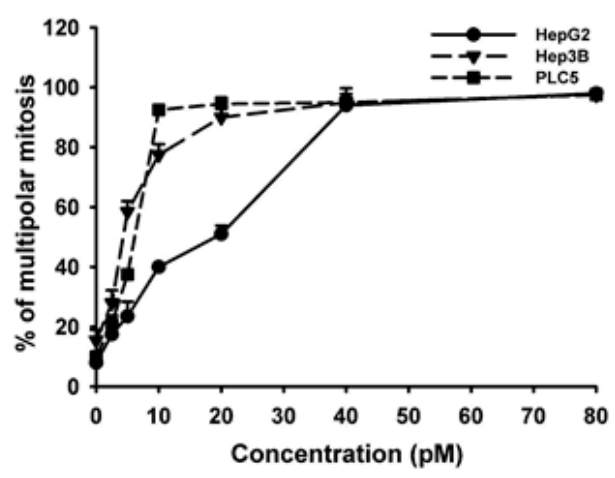

Figure 2. (A) Cell viability analysis. Cells were treated with LGI-147 at the indicated concentrations for $72 \mathrm{~h}$, and their viability was calculated using the trypan blue exclusion assay. (B) Activity of kinesin motor proteins. Purified Eg5, CENP-E, MKLP-1, and BimC underwent a cell-free kinesin ATPase end-point assay either under 50 pM of LGI-147 or not. Values shown are percentages of inhibition corrected by the controls. (C,D) Accumulation of abnormal mitotic cells (indicated by the arrows) due to LGI-147 treatment. After $24 \mathrm{~h}$ of treatment with the indicated concentrations of LGI-147, the HCC cells were fixed and stained with an anti- $\alpha$-tubulin antibody (green). (C) Images shown are experiments on PLC5 cells captured through a fluorescence microscope. (D) Quantified results of Figure 2C. 
A

\section{HepG2}

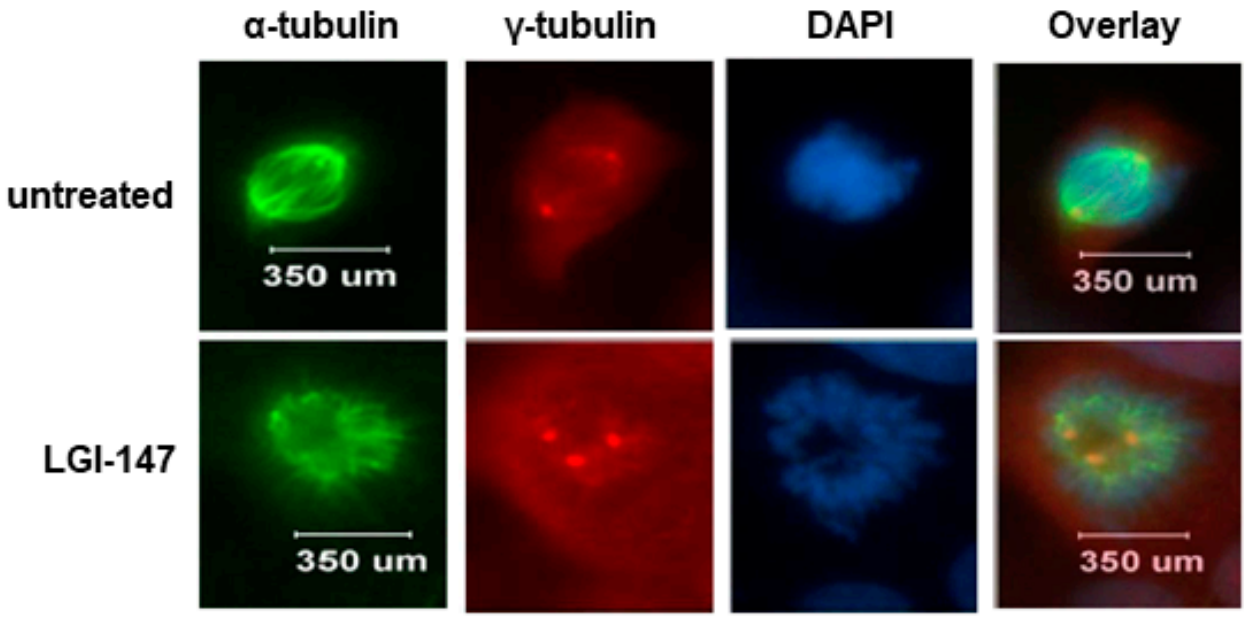

B

\section{Hep3B}

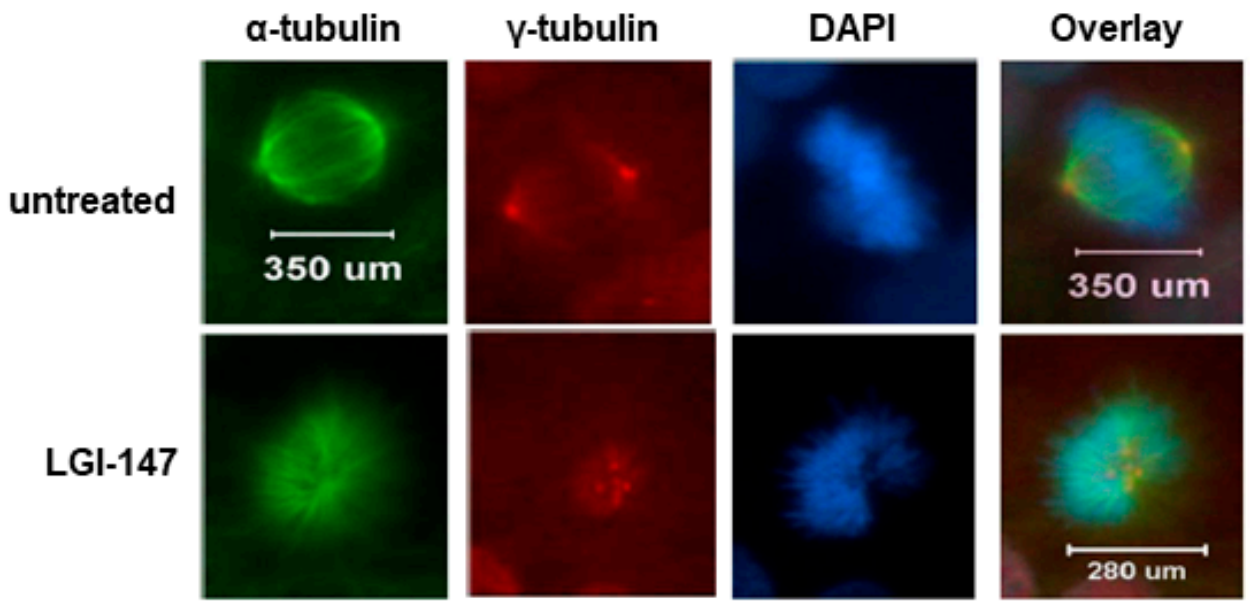

C

\section{PLC5}

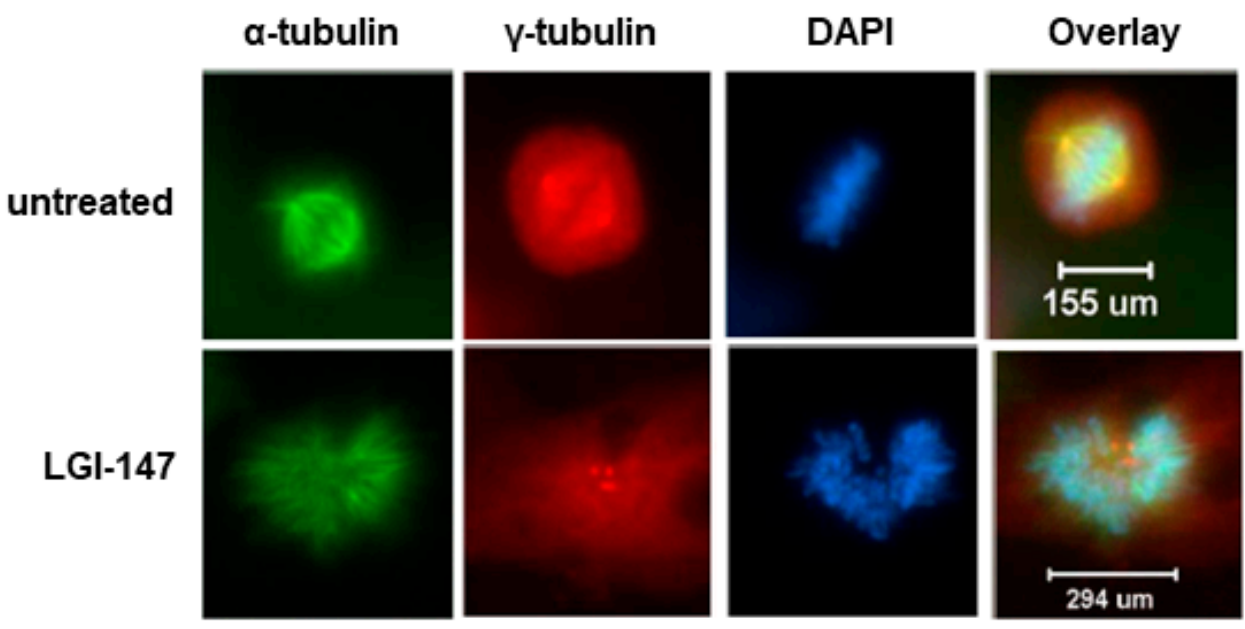

Figure 3. (A-C) Abnormal monopolar spindle formation in HCC cells under LGI-147 treatment during prometaphase. After $24 \mathrm{~h}$ treatment with the vehicle or $50 \mathrm{pM}$ of LGI-147, the HCC cells were fixed and stained with anti- $\alpha$-tubulin (green) and anti- $\gamma$-tubulin antibodies (red) and DAPI (blue). The images were captured using a confocal microscope $(63 \times$ objective). 
Because mitotic interference may induce cell cycle disturbance and cell death, we investigated the effects of LGI-147 on HCC cell cycle progression and apoptosis. As shown in Figure 4A, Eg5 inhibition by LGI-147 treatment resulted in time-dependent cell cycle arrest and accumulation of tetraploid cells. LGI-147 treatment also led to the appearance of octoploid cells, which preceded cell death, particularly in the PLC5 cell line.

A

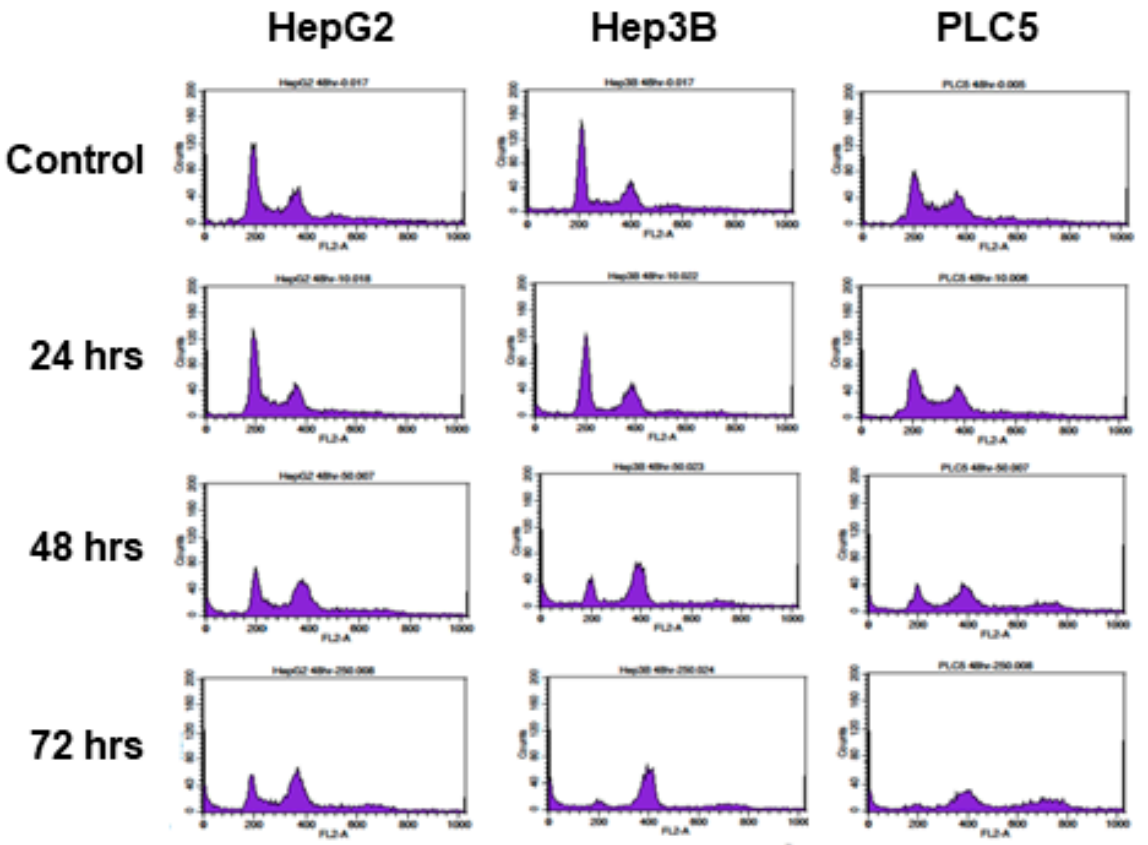

B

LGI-147 for 72 hrs

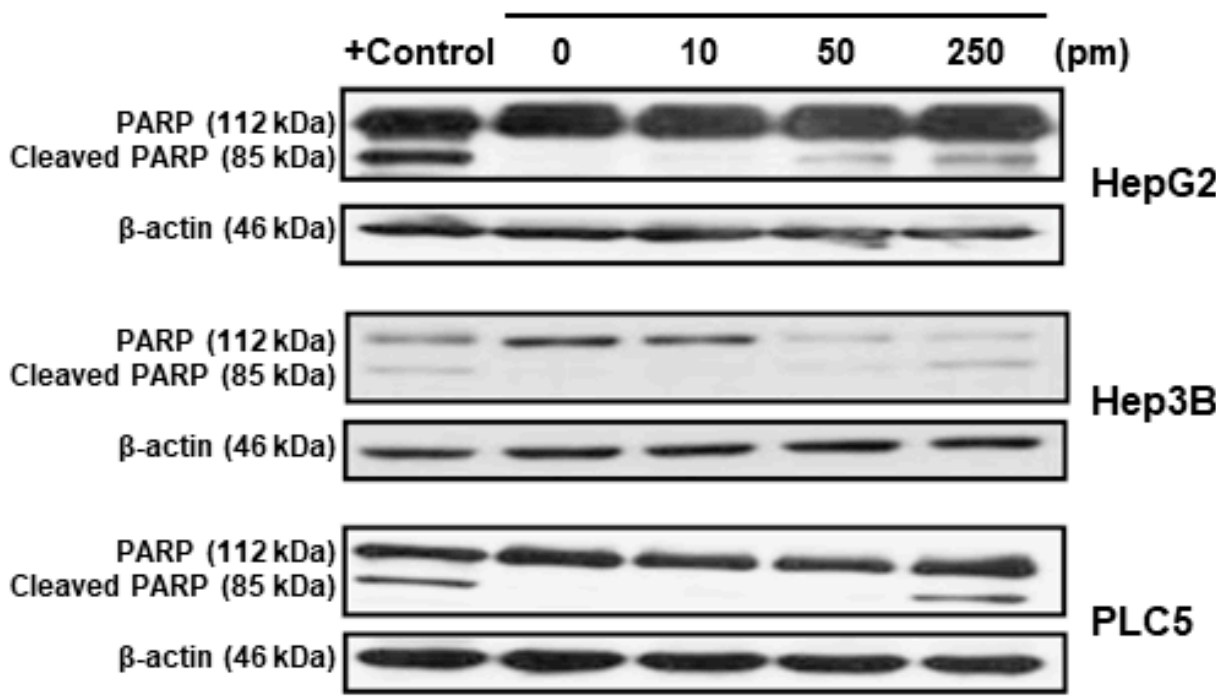

Figure 4. (A) Cell cycle disturbance in the HCC cells. Cells were treated with 50 pM LGI-147 for 24 to $72 \mathrm{~h}$, and then stained with propidium iodide. DNA content was analyzed using the flow cytometry. Data shown are representative of three independent experiments. (B) Cell apoptosis. The HCC cells were treated with a vehicle, positive control ( $1 \mu \mathrm{M}$ doxorubicin), or indicated concentrations of LGI-147 for $72 \mathrm{~h}$. PARP cleavage was detected using Western blotting.

Eg5 inhibition by LGI-147 treatment also induced dose-dependent apoptosis. After $72 \mathrm{~h}$ LGI-147 treatment, PARP cleavage was detected (Figure 4B), and the sub-G1 fractions 
of the HCC cells increased significantly ( $p<0.05$, Figure 5A), particularly under an LGI-147 concentration of $\geq 50 \mathrm{pM}$.

A

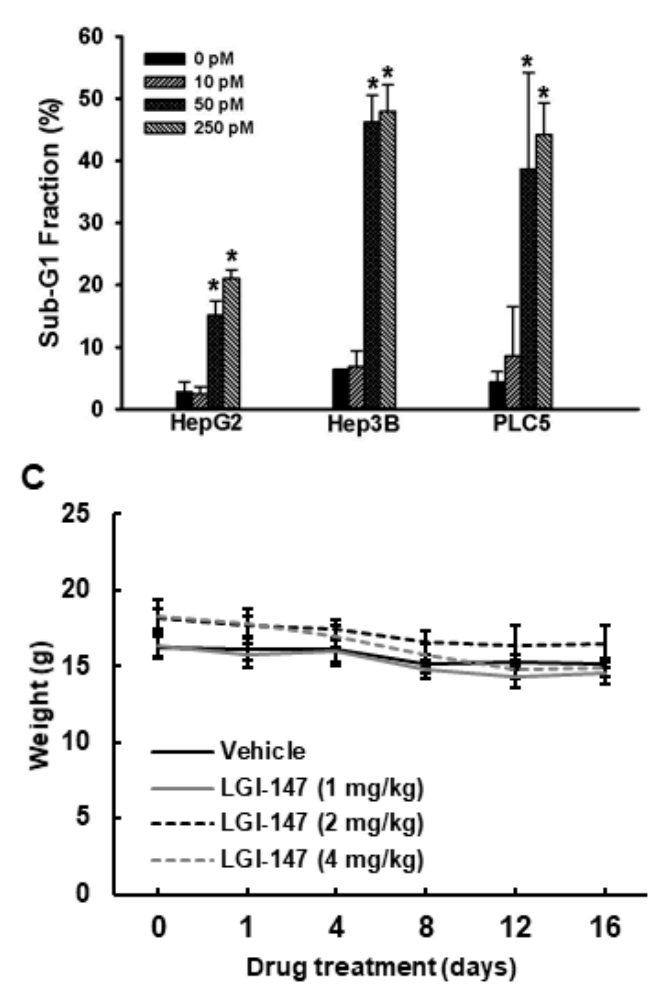

B
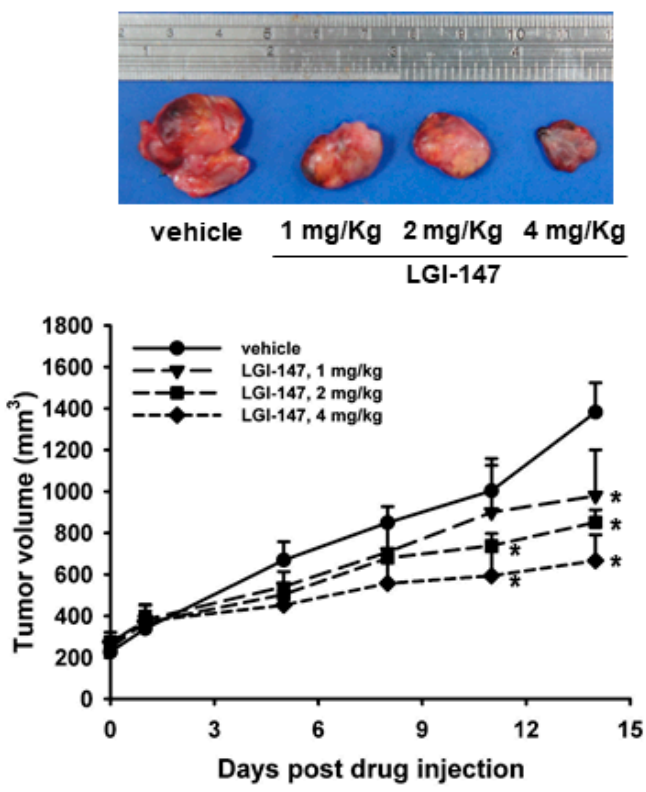

Figure 5. (A) Apoptosis due to Eg5 inhibition. Sub-G1 DNA content in HCC cells treated with vehicle or LGI-147 at the indicated concentrations for $72 \mathrm{~h}$. The percentage of cells with sub-G1 DNA content is shown. Columns denote means, and bars denote standard deviations $(\mathrm{n}=3) .{ }^{*}, p<0.05$. (B,C) Suppression of in vivo tumor growth by LGI-147. PLC5 cells were injected subcutaneously into 5 -week-old BALC/c mice ( $\mathrm{n}=6$ per group). When tumor volume reached approximately $200 \mathrm{~mm}^{3}$, the mice were treated with intravenous injections of LGI-147 twice a week at the indicated doses. (B) Tumor size was estimated twice a week, and (C) body weight was monitored daily.

\subsection{Eg5 Inhibition Reduced In Vivo HCC Tumor Growth}

To determine the in vivo antitumor efficacy of LGI-147, a PLC5 xenograft model was established. PLC5 tumor growth was significantly suppressed by LGI-147 treatment (Figure 5B). At day 14 of LGI-147 treatment, the mean tumor volumes of mice treated at $2 \mathrm{mg} / \mathrm{Kg}\left(851.97 \mathrm{~mm}^{3}\right)$ and $4 \mathrm{mg} / \mathrm{kg}\left(666.94 \mathrm{~mm}^{3}\right)$ were significantly lower than that of the control group (1382.21 $\mathrm{mm}^{3} ; p<0.05$ for both). Mouse weight did not differ significantly between groups (Figure 5C).

\section{Discussion}

In this study, we observed an association between high tumor expression of $E g 5$ and poor HCC prognosis. The 24-month OS rates of patients with low and high Eg5 expression of $75 \%$ and $41.7 \%$ differed substantially. Even after adjustment for other clinicopathological variables, Eg 5 expression remained an independent predictor of OS and DFS. The preclinical HCC models demonstrated the therapeutic potential of $E g 5$ inhibition through a novel $E g 5$ inhibitor, LGI-147. Eg5 inhibition by LGI-147 interfered with mitosis, halted the cell cycle, and induced apoptosis in the HCC cells. The HCC xenograft model also demonstrated the in vivo antitumor efficacy of LGI-147.

Inhibition of cell proliferation through mitosis is a clinically effective anticancer intervention [23]. As our previous studies have demonstrated, the overexpression of Aurora kinases A and B, essential mitotic kinases, in HCC cells is associated with poor HCC 
prognosis $[7,9]$. Furthermore, Aurora kinase inhibitors have potent anticancer effects in human HCC [7,9]. Elucidation of the prognostic significance of $E g 5$ expression and the antitumor efficacy of specific $E g 5$ inhibitors is essential to establish $E g 5$ as a therapeutic target for HCC. Therefore, the findings of the present study provide a rationale for the clinical development of specific $E g 5$ inhibitors for HCC treatment. Our findings regarding the prognostic value of $E g 5$ expression are generally consistent with those of a previous study [24], although that study did not analyze DFS.

The past decade has seen the identification of multiple anticancer small-molecule inhibitors targeting mitotic machinery, including Aurora kinases, Polo-like kinase 1, Eg5, and CENP-E. Their cellular consequences are typically disturbance of the cell cycle, suppression of cell proliferation, and induction of apoptosis at mitotic phase or following mitotic slippage [25]. Eg5 is a promising anticancer therapeutic target because, as with other kinesins such as CENP-E, it is critically involved in centrosome maturation, spindle assembly, chromosome segregation, and cytokinesis [16]. In the current study, we used LGI-147, a specific Eg5 inhibitor that did not inhibit the activity of other kinesins such as CENP-E, MKLP-1, and BimC. The IC ${ }_{50}$ of LGI-147 on cell viability at the pM level was extremely low. The therapeutic potential of other Eg5 inhibitors such as AZD4877 [26,27] and filanesib [28-30] has been demonstrated in several phase I or II clinical trials for cancers other than HCC. Our findings may provide a basis for the development of LGI-147 or other Eg5 inhibitors as HCC therapeutics.

Our study had some limitations. First, we only used one method of Eg5 inhibition because we did not have access to Eg5 inhibitors other than LGI-147. However, as mentioned, LGI-147 had high specificity; therefore, the possibility of an off-target effect of LGI-147 as the primary mechanism is low. Second, we did not examine the peripheral blood cell counts of mice under LGI-147 treatment. Because mitosis inhibitors may affect all dividing cells, bone marrow suppression can be primary toxicity. However, such problems can be addressed in phase 1 clinical trials or resolved through scheduling. In in vivo studies, tumor size reduction may result from mechanisms other than apoptosis, such as tissue inflammatory or stromal changes. These should be explored in further research.

In conclusion, high Eg5 expression was associated with poor HCC prognosis. Eg5 inhibition with LGI-147 demonstrated promising in vitro and in vivo efficacy against HCC cells, suggesting that $E g 5$ is a potential clinical prognostic factor and therapeutic target for HCC.

Author Contributions: Y.-Y.S.: formal analysis, writing—original draft; N.-Y.S.: conceptualization, data curation, investigation, writing —original draft; Y.-M.J.: methodology; Y.-M.W.: resources; C.H.: resources; C.-H.H.: resources; H.-C.H.: methodology, writing-review and editing; A.L.C.: funding acquisition, supervision; Z.-Z.L.: conceptualization, funding acquisition, investigation, writing-review and editing. All authors have read and agreed to the published version of the manuscript.

Funding: This study was supported by grants from the Ministry of Science and Technology, Taiwan (MOST-105-2314-B-002-194, MOST 106-2314-B-002-213, MOST-108-2314-B-002-072-MY3, and MOST 109-2314-B-002-233-MY3), National Taiwan University Hospital (NTUH.106-003589), and Liver Disease Prevention \& Treatment Research Foundation, Taiwan (108-141).

Institutional Review Board Statement: The study was conducted according to the guidelines of the Declaration of Helsinki and approved by the Research Ethics Committee of National Taiwan University Hospital (protocol code 201812025RINA; 3 December 2020).

Informed Consent Statement: Not applicable.

Data Availability Statement: All data of this study were included in this manuscript.

Conflicts of Interest: None declared. 


\section{References}

1. Shao, Y.Y.; Liu, T.H.; Lee, Y.H.; Hsu, C.H.; Cheng, A.L. Modified CLIP with objective liver reserve assessment retains prognosis pre-diction for patients with advanced hepatocellular carcinoma. J. Gastroenterol. Hepatol. 2016, 31, 1336-1341. [CrossRef] [PubMed]

2. Finn, R.S.; Qin, S.; Ikeda, M.; Galle, P.R.; Ducreux, M.; Kim, T.-Y.; Kudo, M.; Breder, V.; Merle, P.; Kaseb, A.O. Atezolizumab plus Bevacizumab in Unresectable Hepatocellular Carcinoma. N. Engl. J. Med. 2020, 382, 1894-1905. [CrossRef]

3. Liu, T.-H.; Shao, Y.-Y.; Hsu, C.-H. It takes two to tango: Breakthrough advanced hepatocellular carcinoma treatment that combines anti-angiogenesis and immune checkpoint blockade. J. Formos. Med. Assoc. 2021, 120, 1-4. [CrossRef]

4. Finn, R.S.; Ikeda, M.; Zhu, A.X.; Sung, M.W.; Baron, A.D.; Kudo, M.; Okusaka, T.; Kobayashi, M.; Kumada, H.; Kaneko, S.; et al. Phase $\mathrm{Ib}$ Study of Lenvatinib Plus Pembrolizumab in Patients with Unresectable Hepatocellular Carcinoma. J. Clin. Oncol. 2020, 38, 2960-2970. [CrossRef] [PubMed]

5. $\quad$ Lee, M.S.; Ryoo, B.-Y.; Hsu, C.-H.; Numata, K.; Stein, S.; Verret, W.; Hack, S.P.; Spahn, J.; Liu, B.; Abdullah, H.; et al. Atezolizumab with or without bevacizumab in unresectable hepatocellular carcinoma (GO30140): An open-label, multicentre, phase 1b study. Lancet Oncol. 2020, 21, 808-820. [CrossRef]

6. Shao, Y.-Y.; Wu, C.-H.; Lu, L.-C.; Chan, S.-Y.; Ma, Y.-Y.; Yen, F.-C.; Hsu, C.-H.; Cheng, A.-L. Prognosis of patients with advanced hepatocellular carcinoma who failed first-line systemic therapy. J. Hepatol. 2014, 60, 313-318. [CrossRef] [PubMed]

7. Lin, Z.-Z.; Jeng, Y.-M.; Hu, F.-C.; Pan, H.-W.; Tsao, H.-W.; Lai, P.-L.; Lee, P.-H.; Cheng, A.-L.; Hsu, H.-C. Significance of Aurora B overexpression in hepatocellular carcinoma. Aurora B Overexpression in HCC. BMC Cancer 2010, 10, 461. [CrossRef] [PubMed]

8. Lin, Z.-Z.; Hsu, H.-C.; Hsu, C.-H.; Yeh, P.-Y.; Huang, C.-Y.F.; Huang, Y.-F.; Chen, T.-J.; Kuo, S.-H.; Hsu, C.; Hu, F.-C.; et al. The Aurora kinase inhibitor VE-465 has anticancer effects in pre-clinical studies of human hepatocellular carcinoma. J. Hepatol. 2009, 50, 518-527. [CrossRef]

9. Jeng, Y.-M.; Peng, S.-Y.; Lin, C.-Y.; Hsu, H.-C. Overexpression and Amplification of Aurora-A in Hepatocellular Carcinoma. Clin. Cancer Res. 2004, 10, 2065-2071. [CrossRef]

10. Huszar, D.; Theoclitou, M.-E.; Skolnik, J.; Herbst, R. Kinesin motor proteins as targets for cancer therapy. Cancer Metastasis Rev. 2009, 28, 197-208. [CrossRef] [PubMed]

11. Sarli, V.; Giannis, A. Targeting the Kinesin Spindle Protein: Basic Principles and Clinical Implications. Clin. Cancer Res. 2008, 14, 7583-7587. [CrossRef] [PubMed]

12. Castillo, A.; Morse, H.C., 3rd; Godfrey, V.L.; Naeem, R.; Justice, M.J. Overexpression of Eg5 causes genomic instability and tumor formation in mice. Cancer Res. 2007, 67, 10138-10147. [CrossRef]

13. Jin, Q.; Huang, F.; Wang, X.; Zhu, H.; Xian, Y.; Li, J.; Zhang, S.; Ni, Q. High Eg5 expression predicts poor prognosis in breast cancer. Oncotarget 2017, 8, 62208-62216. [CrossRef]

14. Lu, M.; Zhu, H.; Wang, X.; Zhang, D.; Xiong, L.; Xu, L.; You, Y. The prognostic role of Eg5 expression in laryngeal squamous cell car-cinoma. Pathology 2016, 48, 214-218. [CrossRef]

15. Miglarese, M.R.; Carlson, R.O. Development of new cancer therapeutic agents targeting mitosis. Expert Opin. Investig. Drugs 2006, 15, 1411-1425. [CrossRef] [PubMed]

16. Rath, O.; Kozielski, F. Kinesins and cancer. Nat. Rev. Cancer 2012, 12, 527-539. [CrossRef]

17. Giantulli, S.; De Iuliis, F.; Taglieri, L.; Carradori, S.; Menichelli, G.; Morrone, S.; Scarpa, S.; Silvestri, I. Growth arrest and apoptosis induced by kinesin Eg5 inhibitor K858 and by its 1,3,4-thiadiazoline analogue in tumor cells. Anti-Cancer Drugs 2018, $29,674-681$. [CrossRef] [PubMed]

18. Wang, Y.; Wu, X.; Du, M.; Chen, X.; Ning, X.; Chen, H.; Wang, S.; Liu, J.; Liu, Z.; Li, R.; et al. Eg5 inhibitor YL001 induces mitotic arrest and inhibits tumor prolif-eration. Oncotarget 2017, 8, 42510-42524. [CrossRef] [PubMed]

19. Ye, X.S.; Fan, L.; Van Horn, R.D.; Nakai, R.; Ohta, Y.; Akinaga, S.; Murakata, C.; Yamashita, Y.; Yin, T.; Credille, K.M.; et al. A Novel Eg5 Inhibitor (LY2523355) Causes Mitotic Arrest and Apoptosis in Cancer Cells and Shows Potent Antitumor Activity in Xenograft Tumor Models. Mol. Cancer Ther. 2015, 14, 2463-2472. [CrossRef]

20. Nakai, R.; Iida, S.-I.; Takahashi, T.; Tsujita, T.; Okamoto, S.; Takada, C.; Akasaka, K.; Ichikawa, S.; Ishida, H.; Kusaka, H.; et al. K858, a Novel Inhibitor of Mitotic Kinesin Eg5 and Antitumor Agent, Induces Cell Death in Cancer Cells. Cancer Res. 2009, 69, 3901-3909. [CrossRef] [PubMed]

21. Lin, Z.; Hsu, C.; Jeng, Y.; Hu, F.; Pan, H.; Wu, Y.; Hsu, H.; Cheng, A. Klotho-beta and fibroblast growth factor 19 expression correlates with early recurrence of resectable hepatocellular carcinoma. Liver Int. 2019, 39, 1682-1691. [CrossRef] [PubMed]

22. Holland, J.P.; Kang, A.; Cohrs, S.; Selivanova, S.V.; Milicevic Sephton, S.; Betzel, T.; Frey, D.; Wieser, M.; Jaussi, R.; Kammerer, R.A.; et al. Synthesis and evaluation of biphenyl com-pounds as kinesin spindle protein inhibitors. Chem. Biodivers. 2013, 10, 538-555. [CrossRef] [PubMed]

23. Salmela, A.-L.; Kallio, M.J. Mitosis as an anti-cancer drug target. Chromosoma 2013, 122, 431-449. [CrossRef] [PubMed]

24. Liu, C.; Zhou, N.; Li, J.; Kong, J.; Guan, X.; Wang, X. Eg5 Overexpression Is Predictive of Poor Prognosis in Hepatocellular Carcinoma Patients. Dis. Markers 2017, 2017, 1-9. [CrossRef]

25. Janssen, A.; Medema, R.H. Mitosis as an anti-cancer target. Oncogene 2011, 30, 2799-2809. [CrossRef]

26. Jones, R.; Vuky, J.; Elliott, T.; Mead, G.; Arranz, J.A.; Chester, J.; Chowdhury, S.; Dudek, A.Z.; Mueller-Mattheis, V.; Grimm, M.-O.; et al. Phase II study to assess the efficacy, safety and tolerability of the mitotic spindle kinesin inhibitor AZD4877 in patients with recurrent advanced urothelial cancer. Investig. New Drugs 2013, 31, 1001-1007. [CrossRef] [PubMed] 
27. Kantarjian, H.M.; Padmanabhan, S.; Stock, W.; Tallman, M.S.; Curt, G.A.; Li, J.; Osmukhina, A.; Wu, K.; Huszar, D.; Borthukar, G.; et al. Phase I/II multicenter study to assess the safety, tolerability, pharmacokinetics and pharmacodynamics of AZD4877 in patients with refractory acute myeloid leukemia. Investig. New Drugs 2011, 30, 1107-1115. [CrossRef] [PubMed]

28. Lee, H.C.; Shah, J.J.; Feng, L.; Manasanch, E.E.; Lu, R.; Morphey, A.; Crumpton, B.; Patel, K.K.; Wang, M.L.; Alexanian, R.; et al. A phase 1 study of filanesib, carfilzomib, and dexamethasone in patients with relapsed and/or refractory multiple myeloma. Blood Cancer J. 2019, 9, 1-5. [CrossRef]

29. Lorusso, P.M.; Goncalves, P.H.; Casetta, L.; Carter, J.A.; Litwiler, K.; Roseberry, D.; Rush, S.; Schreiber, J.; Simmons, H.M.; Ptaszynski, M.; et al. First-in-human phase 1 study of filanesib (ARRY-520), a kinesin spindle protein inhibitor, in patients with advanced solid tumors. Investig. New Drugs 2015, 33, 440-449. [CrossRef]

30. Shah, J.J.; Kaufman, J.L.; Zonder, J.A.; Cohen, A.D.; Bensinger, W.I.; Hilder, B.W.; Rush, S.A.; Walker, D.H.; Tunquist, B.J.; Litwiler, K.S.; et al. A Phase 1 and 2 study of Filanesib alone and in combination with low-dose dexamethasone in relapsed/refractory multiple myeloma. Cancer 2017, 123, 4617-4630. [CrossRef] 